\title{
The Self-Organisation of Strategic Alliances
}

\author{
Andreas Pyka \\ Universität Augsburg \\ and Paul Windrum \\ Manchester Metropolitan University
}

September 2001

JEL: O31; O33; L2

Keywords: Strategic Alliances, Innovation Networks, Self-Organisation

\begin{abstract}
$\underline{\text { Abstract }}$
Strategic alliances form a vital part of today's business environment. The sheer variety of collaborative forms is notable - which include R\&D coalitions, marketing and distribution agreements, franchising, coproduction agreements, licensing, consortiums and joint ventures. Here we define a strategic alliance as a cooperative agreement between two or more autonomous firms pursuing common objectives or working towards solving common problems through a period of sustained interaction. A distinction is commonly made between 'formal' and 'informal' inter-firm alliances. Informal alliances involve voluntary contact and interaction while in formal alliances cooperation is governed by a contractual agreement. The advantage of formal alliances is the ability to put in place IPR clauses, confidentially agreements and other contractual measures designed to safeguard the firm against knowledge spill-over. However, these measures are costly to instigate and police. By contrast, a key attraction of informal relationships is their low co-ordination costs. Informal know-how trading is relatively simple, uncomplicated and more flexible, and has been observed in a number of industries.
\end{abstract}

A number of factors affecting firms' decisions to cooperate or not cooperate within strategic alliances have been raised in the literature. In this paper we consider three factors in particular: the relative costs of coordinating activity through strategic alliances vis-à-vis the costs of coordinating activity in-house, the degree of uncertainty present in the competitive environment, and the feedback between individual decision-making and industry structure. Whereas discussion of the first two factors is well developed in the strategic alliance literature, the third factor has hitherto only been addressed indirectly. The contribution to this under-researched area represents an important contribution of this paper to the current discourse. In order to focus the discussion, the paper considers the formation of horizontal inter-firm strategic alliances in dynamic product markets. These markets are characterised by rapid rates of technological change, a high degree of market uncertainty, and high rewards (supernormal profits) for successful firms offset by shortening life cycles.

\footnotetext{
* Andreas Pyka, Universität Augsburg, Institut für VWL, Universitätsstr. 16, 86159 Augsburg, e-mail: andreas.pyka@wiso.uni-augsburg.de

^ Paul Windrum, Manchester Metropolitan University, Economics Department, Aytoun Building, Aytoun

Street, Manchester, M1 3GH, e-mail: p.windrum@mmu.ac.uk
} 


\section{INTRODUCTION*}

Strategic alliances form a vital part of today's business environment. The sheer variety of collaborative forms is notable - which include R\&D coalitions, marketing and distribution agreements, franchising, co-production agreements, licensing, consortiums and joint ventures - as is the range of suggested benefits attributable to the formation of strategic alliances. The suggested benefits include the reduction of barriers to foreign entry (Beamish and Banks, 1987; Banerji and Sambharya, 1998), firm emergence and growth (Hansen, 1995; Larson and Starr, 1993; Stuart, Hoang and Hybels, 1999), the reduction of environmental uncertainty (Dickson and Weaver, 1997), internalisation (Yoshino and Rangan, 1995), meeting technological needs (Hagedoorn, 1993; Tyler and Steensma, 1995), and learning (Lundvall and Johnson, 1994; Powell, Koput, and SmithDoerr, 1996).

Here we define a strategic alliance as a cooperative agreement between two or more autonomous firms pursuing common objectives or working towards solving common problems through a period of sustained interaction. A distinction is commonly made between 'formal' and 'informal' inter-firm alliances (Ibarra, 1992). Informal alliances involve voluntary contact and interaction while in formal alliances cooperation is governed by a contractual agreement. The advantage of formal alliances is the ability to put in place IPR clauses, confidentially agreements and other contractual measures designed to safeguard the firm against knowledge spill-over. However, these measures are costly to instigate and police. By contrast, a key attraction of informal relationships is their low co-ordination costs. Informal know-how trading is relatively simple, uncomplicated and more flexible, and has been observed in a number of industries (Håkansson and Johanson, 1988; von Hippel, 1989).

A number of factors affecting firms' decisions to cooperate or not cooperate within strategic alliances have been raised in the literature. In this paper we consider three factors in particular: the relative costs of coordinating activity through strategic alliances vis-à-vis the costs of coordinating activity in-house, the degree of uncertainty present in the competitive environment, and the feedback between individual decision-making and industry structure. Whereas discussion of the first two factors is well developed in the strategic alliance literature, the third factor has hitherto only been addressed indirectly (Hite and Hesterly, 2001). The contribution to this under-researched area represents an important contribution of this paper to the current discourse. In order to focus the discussion, the paper considers the formation of horizontal inter-firm strategic alliances in dynamic product markets. These markets are characterised by rapid rates of technological change, a high degree of market uncertainty, and high rewards (supernormal profits) for successful firms offset by shortening life cycles.

\footnotetext{
${ }^{*}$ The authors gratefully acknowledge supportive funding through SEIN-Project, European Commission's Framework 4 Programme, contract\# SOEI-CT-98-1107.
} 
In order to address these research issues, the paper applies the self-organisation modelling approach developed by Eigen, Haken and Prigogine. Following Silverberg's 1 discussion of the relevance of the approach to economics in general, the current paper applies the approach to the study of inter-firm strategic alliances for the first time. The merit of this application will be judged on the ability to highlight new phenomena and/or shed fresh light on previously researched phenomena. For this reason, the paper adopts the following structure. Section 2 of the paper identifies the key properties of selforganising systems: thermodynamic openness, local interaction amongst heterogeneous agents, non-linearlity and emergence. Section 3 compares and contrasts a selforganisation perspective of strategic alliances with the established transaction-cost and resource-based perspectives. This prepares the way for the formal model of strategic alliances presented in section 4. Through this model we consider the implications of coordination costs, dynamic uncertainty, and firm-industry feedbacks on the formation of strategic alliances.

\section{SELF-ORGANISATION THEORY}

Self-organisation theory is, to date, overwhelmingly the product of research conducted in the natural science disciplines of physics, chemistry and biology. Classic contributions to the area include von Bertalanffy (1968), Haken (1978) and Prigogine (1980). The principal characteristics of self-organising systems are outlined by Prigogine (1980), and Forrest and Jones (1994). The fundamental research question addressed is 'Where does order come from?'. The general laws of thermodynamics suggest that dynamic processes will follow a path of least energy until the system finds a thermodynamic equilibrium, where it will remain unless it is externally perturbed. Yet the physical world abounds with systems that maintain a high internal energy and organisation that, at least at first sight, appear to defy the laws of physics. Rather than moving towards a state of maximum entropy (total chaos) it appears that organisation arises from initially disordered conditions.

The first, and most commonly noted, condition for a self-organising physical 'system' (such as an organism or a population) is thermodynamic openness. A self-organising system exchanges energy and/or mass with its environment such that there is a nonzero flow of energy through the system. If this is not the case then, according to the second law of thermodynamics, all available usable energy in the system will be used up and the system will approach a state of maximum entropy (a thermodynamic equilibrium). A system can avoid collapsing into an equilibrium providing it is able to import usable energy from its environment and export entropy back to it. The system does not violate the second law of thermodynamics because it is part of a larger system-environment unit.

\footnotetext{
${ }^{1}$ See Silverberg 1984, 1987; Silverberg, Dosi and Orsenigo, 1988.
} 
This entropy-exporting dynamic is the fundamental feature of what chemists and physicists call dissipative structures. It is often said that physical systems that are selforganising are 'far from' thermodynamic equilibrium. It is presumably more accurate to state that a system only needs to be far enough to avoid collapsing into a local equilibrium condition. If a system is neither at nor near equilibrium, then it will be undergoing some form of change in behaviour and is said to be dynamic.

A second characteristic of self-organising systems is local interaction between heterogeneous individuals or elements. All natural systems have inherently local interactions, every event having some location and some range of effect (Kawata and Toquenaga, 1994). The focus on local interaction goes hand-in-hand with a bottom-up approach to systems modelling that emphasises variety in micro behaviour. Higher-level structures, it is argued, are the product of subtle differences within a heterogeneous community and the local interactions that occur between the individual members (component elements) of a community. Small differences can lead to larger differences, such as changes in the population gene frequencies, size or location that in turn can have cascading effects at still larger scales. This has important implications for methodological practice in both natural and social sciences. One cannot, it is argued, deduce macro behaviour from the behaviour of an 'average' or 'representative' individual. For example, one cannot understand the collective rationality and operation of an ant colony through the study of an individual ant. Equally, one is unable to derive collective rationality in economic phenomena, such as the formation of strategic alliances, through the construction of abstract representative agents. Rather, macro phenomena such as strategic alliances are a product of the interactions of heterogeneous firms. As with the ant colony example, complex dynamics of the macro structure arise from the interaction of heterogeneous individuals pursuing very simple behavioural rules. A self-organisation perspective of strategic alliances highlights the heterogeneity of firms, the rules that govern their individual behaviour, and the rules governing the interaction between firms.

A third characteristic of self-organisation models is the non-linearity of local interactions between the individual agents or elements making up a system. A system may contain a number of feedback loops, some of which are positive and some negative. Selforganisation can either occur when feedback loops exist among component parts, or else between lower and higher hierarchical levels. One of the most interesting, but still imprecise, propositions of self-organisation theory is that of 'emergence' (Crutchfield, 1994). This states that higher-order phenomena can spontaneously arise from the interactions of the lower parts. In itself this does not seem particularly contentious. Indeed emergence is a key property underpinning not just economics but all social theory. If systems were simply reducible to atomistic individuals then there would be no need to investigate the economic (or any other) interactions between individuals. Silverberg et al. (1988) observe that in economics we see "complex interdependent dynamical systems unfolding in historical, i.e. irreversible, time, economic agents, who make decision today the correctness of which will only be revealed considerably later, are confronted with 
irreducible uncertainty and holistic interactions between each other and with aggregate variables" (Silverberg et al., 1988, p.1036, italics in original). Thus the emergence property is linked to the presence of multi-scale effects in self-organising systems. Small-scale interactions produce a 'field' at the macro level that in turn influences and modifies activity at the small-scale.

\section{ALTERNATIVE PERSPECTIVES ON STRATEGIC ALLIANCE FORMATION}

Having identified the key properties of self-organising systems, we next consider its application to the study of strategic alliance formation. As noted above, the core concepts and modelling methods of self-organisation theory have been formulated within natural science disciplines. Transferring and applying these to the social domain is a non-trivial issue which must be conducted with care. Furthermore, the success of such a venture will be judged on the ability to highlight new phenomena and/or shed fresh light on previously researched phenomena. To this end, we contrast the self-organisation perspective with the transaction cost and resource-based perspectives. Both the transaction cost and resource-based perspectives are well established within the area. Of course it is beyond the scope of any single paper to conduct a comparison that considers all possible types and modes of strategic alliance. Hence, for the purpose of this paper, we narrow the scope of the discussion to the formation of horizontal alliances through which firms seek to strategically cooperate in their innovation policies. Of particular importance is the way in which different 'stylised facts' of innovation in dynamic markets can be brought together under the self-organisation rubric. The analysis in turn prepares the way for the formal model of strategic alliances presented in section 4 and its consideration of coordination costs, dynamic uncertainty, and firm-industry feedbacks on the formation of strategic alliances.

\subsection{Transactions cost analysis}

The transactions cost approach to strategic alliances is perhaps the most well developed in the area. According to this approach, economising on transactions costs is the most important criterion affecting the choice of governance structure for economic coordination. In transaction cost economics, a firm's ownership decision centres on minimising the sum of transaction costs and production costs. Transactions costs are incurred by activities associated with exchange - notably, the writing and enforcing of contracts - while production costs are those costs of learning, organising and managing production arising from the coordination of activities in-house. The cost of writing and enforcing of contracts is affected by five factors: asset specificity, uncertainty, information 
asymmetry, frequency of transactions, and opportunism (Williamson, 1975). Since the internalisation of activities is an effective means of controlling transactions costs, internal development within the firm will be preferred when the transactions costs of an exchange are high and production costs are low. By contrast, market exchanges will be preferred when production costs are high and transaction costs are low.

The original focus of Williamson's seminal work on transactions costs (Williamson, $1975,1981)$ was the rise of hierarchies in response to market failures. The proliferation of strategic alliances in the 1980s and 1990s was largely beyond the explanatory scope of the theory. Responding to this criticism, Williamson $(1983,1991)$ and other transaction cost theorists (e.g. Anderson and Gatignon, 1986; Hennart, 1988; Jones and Hill, 1988) have sought to extend the analysis by viewing strategic alliances as a hybrid mode of governance between markets and the internal coordination of production. Strategic alliances combine features of internalisation and market exchanges because a joint venture partially internalises an exchange. Contracts are still needed but, since these are often incomplete, much of the activity will be left to joint coordination. According to the transactions costs approach, alliances are preferred when transactions costs are intermediate. However, if a transaction is characterised by a high degree of asset specificity then it will be handled internally within a single firm. If an alliance is established under such conditions then, the transaction costs approach predicts, it will be unstable due to the high risk of opportunistic behaviour amongst the partners.

\subsection{Resource-based perspective}

Asset specificity is the cornerstone of the resource-based approach, although its perspective and predictions differ significantly to the transactions costs approach. The resource-based approach emphasises value maximisation (as opposed to cost minimisation) through the pooling and utilisation of valuable resources. Forging an alliance enables a firm to focus resources on its core skills and competences while acquiring other components or capabilities it cannot obtain through markets. There are two primary motives for participating in a strategic alliance: to acquire allies' organisational know-how and other resources, or to retain and develop one's own resources by combining them with another's resources (Kogut, 1988; Prahalad and Hamel, 1990).

The resource-based approach dates back to the work of Penrose (1959), who views the firm as a bundle of physical, human and organisational resources. Physical resources include tangible assets such as land, plant and equipment, as well as intangible assets such as brand name, copyright and patents. Human resources include the education, training, experience and skills of individual staff, while organisational resources include corporate culture, organisational structure, rules and procedures of the firm. Penrose emphasises that 
it is the services of these resources which are of interest, not the resources in and of themselves. The capability of a firm is its capacity to perform an activity as a result of organising and coordinating the productive services of a group of resources.

Resource-based theorists highlight the heterogeneity of resource portfolios across firms (Barney, 1991). Valuable resources (or 'competences') are to a greater or lesser extent firm-specific and cumulative. They are usually scarce, imperfectly imitable, and lacking in direct substitutes because they partly take the form of tacit knowledge, and are embedded in individual employees, teams, organisation structures and organisation cultures. As a consequence, learning is cumulative and path-dependent, and in turn affects the absorptive capacity of firms, maintaining resource heterogeneity over time (Nelson and Winter, 1982; Cohen and Levinthal, 1990; Peteraf, 1993).

The distribution of firm resources are, according to this view, the key factor governing the likelihood of firms entering into strategic alliances. Strategic alliances are preferred when the critical inputs required to pursue an opportunity are owned by different parties and these resources cannot be efficiently obtained through market exchanges or mergers and acquisitions. This may be due to the extent to which assets such as knowledge and technology are highly tacit and are inseparable from the organisational structures, practices and other assets of the owner firms (Dosi, 1988), or where the requisite level of knowledge is lacking and cannot be developed within an acceptable timeframe or cost (Madhok, 1997; Mowery et al., 1998). Under these conditions, firms can mutually benefit through aggregation, sharing or exchanging valuable resources with other firms within a strategic alliance.

The competitive advantage of an alliance, once formed, depends on the extent to which partners' complementary assets are effectively aligned. Each partner should bring to an alliance a unique and non-redundant asset that strengthens the overall resource base of the alliance (Deeds and Hill, 1996; Harrigan, 1985; Hill and Hellriegel, 1994). The predictions of resource-based theorists can differ significantly to those of transaction costs theorists. Notably, whereas transaction costs theory suggests alliances are unstable if assets are highly specific, resource-based theory proposes that, despite assets being highly specific, a strategic alliance will be stable provided the benefits are evenly distributed amongst the members.

A criticism that can be raised against both perspectives is the implicit assumptions made about firms' processing capabilities. Despite both views accepting notions of bounded rationality, the learning rules that are specified are highly demanding and unlikely to be met in reality. This is most pronounced in the transactions cost approach but, equally, it is prevalent in the resource-based approach. Take, for example, von Hippel's (1989) study of informal know-how trading. Von Hippel suggests that informal know-how trading is a voluntary exchange of technical information and, as such, represents a 
process designed to initiate technological spill-overs. There are, he argues, good strategic reasons for this. If the value of the information each firm is willing to release is less than the expected value of reciprocated information then firms will exchange their knowledge voluntarily. The argument is interesting but, for this process to continue over time, strong assumptions are made about firms' abilities to evaluate and process information and its potential value.

Empirically, much of the debate between transaction cost and resource-based theories has focused on the costs of coordinating activity through strategic alliances compared with the costs of coordination within the integrated firm. Transaction cost scholars have tended to highlight those costs associated with coordinating activity within alliances that are not by the integrated firm. Notably, partnering firms incur costs associated with searching for reliable partners and designing contracts and other mechanisms that discourage opportunism and monitor the behaviour of alliance partners (Klein et al., 1978; Kranton, 1996). In favour of internal integration, transaction costs writers have emphasised that contracts are an extremely imperfect tool for controlling opportunism (Crocker and Masten, 1991). At the same time, researchers such as Lyons et al. (1990) and Cavantio (1992) argue that the costs of coordinating activity within alliances outweigh the benefits.

Resource-based scholars observe that the transaction cost contribution tends to be biased, both in its neglect of coordination costs associated with activities conducted within the integrated firm and the narrowing of discussion to contacts to the neglect of other forms of monitoring and control. Resource-based scholars highlight empirical evidence that suggests increasing the relational content of an exchange - through the formation of trust relationships, continuity expectations and communication strategies - discourages opportunistic behaviour (Noordeweir et al., 1990; Heide and Miner, 1992; Ring and van de Ven, 1992). The tangible and non-tangible assets created within an alliance can also deter opportunistic behaviour. These include non-recoverable assets such as limited purpose technology, and specialised physical assets and know-how that have limited value outside the alliance (Parkhe, 1993). Finally, there is evidence to suggest that (re)negotiation costs associated with contracts are not constant but fall over time as a strategic alliance matures (Artz and Bush, 2000).

The theoretical and empirical debates between transaction cost and resource-based scholars omit a number of key issues which, we suggest, are as important as relative costs of coordination and the degree of asset specificity. Notably, there is the degree to which decisions are affected by the institutional conditions prevailing within an industry, and the relationship market uncertainty and asset specificity. Transaction cost and resourcebased theories both assume that market uncertainty and asset specificity are independent variables. Yet market uncertainty may actually be a catalyst driving asset specific investments (also see Artz and Bush, 2000). In this event, debates regarding relative coordination costs largely miss the point. Research should focus on the extent to which 
different levels of market uncertainty affect the formation of strategic alliances. In order to begin unpacking these issues, we next consider a self-organisation perspective of strategic alliances.

\subsection{SELF-ORGANISATION PERSPECTIVE}

The self-organisation perspective can be used to bring together a series of stylised facts of innovation that are not readily dealt with by either the transaction cost or the resourcebased perspective. We shall proceed by applying the four key principles of selforganisation: thermodynamic openness, local interaction, non-linearity, and emergence.

\subsubsection{Thermodynamic openness}

In contrast to the internalist approaches of both transaction cost and resource base theories, the self-organisation approach seeks to explain the maintenance of variety and internal organisational stability through thermodynamic openness with the external environment. In order to operationalise the self-organisation approach, one must first define the system and its environment. The system is the object of analysis. In this case the system is the industrial sector in which factors may be operating to encourage the formation of strategic alliances in innovation. These sectors are thermodynamically open with respect to technological innovations in other sectors and also to the application and development of new scientific breakthroughs. Interactions between scientific and technological knowledge bases are complex and non-linear with numerous feedbacks (Freeman, 1974; Swann, 1996). The chain-link model of science and technology first developed by Rosenberg and Kline (Rosenberg, 1982; Kline and Rosenberg, 1986; Rosenberg, 1992) highlights the multitude of interactions that link every phase of the innovation process within industrial organisations and the wider economic, scientific and technological environment in which organisations operate. New knowledge generated in one area can therefore have multiple positive spill-over effects as it diffuses across other areas. Technological evolution is also characterised by mutual interdependencies between different core technologies. New opportunities can be created through the fusion and synthesis of what were previously thought to be unrelated knowledge fields (Basalla, 1988; Mokyr, 1990; Kodama, 1996). Kodama (1996), for example, has highlighted the ability of Japanese companies, operating in stable keiretzu networks, to identify new mutual interdependencies between different core technologies.

The existence of these complex interwoven linkages is an important factor in explaining why R\&D ties can extend well beyond one product life cycle. Additionally, a link has been suggested between the increased prevalence of collaboration and the increasing 
complexity of the problem-solving process. First, the number of different knowledge fields that must be mastered has proliferated (Senker and Faulkner, 1992; Kodama, 1996). Second, the rate of technical and scientific change appears to be increasing. Consequently no single firm has sufficient resources to maintain itself at the leading-edge of knowledge. The upshot has been the emergence of a new organisational structure strategic alliances - in order to manage innovation within dynamic market environments. Firms have coped with the demand for new technologies not only by building up substantial research capacities but also by research cooperation: inter-firm and firmacademic cooperation and other research institutions (Lundvall, 1992).

Through the concept of thermodynamic openness one can usefully consider the interaction between changes in the external environment and changes in firms' internal organisation. In the face of increased technological uncertainty due to high rates of technological change, shortening product life cycles and the need to master and synthesis multiple technologies, strategic alliances offer a means of reducing risk by reducing each firm's exposure in a new technology field and by increasing leverage over the innovation process. In adopting this form of structural organisation, firms seek to maintain relative stability within their institutions while simultaneously generating supernormal profits through high rates of product and process innovation. This drive for relative internal stability in the face of high market uncertainty is not readily dealt with by transactions cost approach.

The issue of supernormal profits also exposes problems in the resource-base approach. Dynamic product markets are characterised by both a rapid rate of technological change and by the rapid diffusion of new ideas and technologies (Abernathy and Utterback, 1975). It is these twin conditions that encourage the development of radically new products in order to capture premium market segments or to pre-empt competitors' entry (Utterback, 1994). Through product innovation, a firm proactively seeks to push out the technological frontier in order to influence the industry's evolution in its favour by shaping product design and configuration, establishing the rules of competition in its favour. A high degree of uncertainty and fluidity is associated with the creation and introduction of radically new technology products. Uncertainty with respect to market size, product design, consumer tastes and technological constraints often leads to a variety of designs being offered, reflecting different firms' bets about the future. As highlighted in the literature on product life cycles, the period of technological uncertainty may end following the emergence of one or a small number of designs that are stable enough (i.e. profitable and technically feasible) to support a significant volume of production (Dalle, 1997; Windrum and Birchenhall, 1998). However, as Schumpeter observed long ago, monopoly or supernormal rents are temporary in dynamic market environments (Schumpeter, 1912). New knowledge generated by their innovative behaviour diffuses into a common knowledge pool and can be built upon by subsequent innovators. 
Tacit and codified knowledge are not fixed entities. Over time, what is initially specialised and tacit knowledge held by individuals is translated into a codified form and transferred. Indeed knowledge transfer is important to the development of both firms and national economies. Modern economic growth theory treats knowledge generation and diffusion as endogenous components of economic development (Romer, 1990; Nelson and Plosser, 1982; Kydland and Prescott, 1982). Further, it is argued that the success of many firms is based on improvements in absorptive capacity - the ability to acquire and assimilate new technological knowledge (Cohen and Levinthal, 1990; Arora and Gambardella, 1994) - and by the ability to internally transfer knowledge between an organisation's business units (Szulanski, 1996). The tacitness of knowledge is thus a short-term phenomenon. The self-organisation perspective of strategic alliance formation developed here emphasises thermodynamic openness - the generation and diffusion of new knowledge across different industrial sectors and between industrial and scientific domains - as the key factor that sustains variety over the long-term.

\subsubsection{Local interaction}

As discussed in section 2, the self-organisation approach places great stress on the inability to deduce macro behaviour from the behaviour of an 'average' or 'representative' individual. Strategic alliances are a product of the interactions of heterogeneous firms. Operationalising the approach therefore not only requires a specification of the dimensions of heterogeneity amongst firms and the rules that govern the individual behaviour of these firms but also the rules governing the interaction between firms. This contrasts sharply with the more traditional methodological approach of both transaction cost theory and resource-based theory. There the procedure is to first construct a representative agent. By assuming that there is no interaction term between the behaviour of this agent and its external environment, the analysis considers the decision-making of this (boundedly) rational agent based on optimisation calculus.

Interdependence in decision-making has been highlighted in the game theoretic literature following Axelrod's $(1980,1981)$ discussion of cooperation in two-person prisoner dilemma models. Axelrod showed that cooperative solutions are possible when agents pursue tit-for-tat strategies and the expected time horizon of the game is infinite. The information gathering and processing demands made upon agents are high in these models: each agent is assumed to know the pay-offs associated with each and every action. Interdependence in decision-making has also been examined in Polya-Urn models by Arthur in his discussion of de facto product standards (Arthur et al., 1985; Arthur et al., 1987; Arthur, 1989). The informational demands made of agents is far more relaxed. Faced by a choice between two alternative technology products, agents are myopic in their decision-making and take into account the prior choices made by other agents in the past. Interdependence leads to path dependency and convergence in the model to one or other alternative. Kirman (1997) notes that path dependency depends on 
two features of the model. The first is an increasing size of population - the Polya Urn model assumes an indefinitely increasing population in order to establish asymptotic results. The second is the strictly sequential nature of decision-making in the model. Bassanini and Dosi (1998) add that the convergence result only strictly holds when returns to adoption are linearly increasing and there is homogeneity of consumer preferences (or at least the degree of heterogeneity is small).

In this paper we are similarly interested in the way in which individual behaviour that is influenced by prevailing conditions; specifically, the degree to which decisions to cooperate are influenced by the degree of cooperation already present in the industry and how this interdependence of decision-making may lead to asymptotic convergence to an equilibrium in which cooperative alliances prevail. Furthermore, we are interested in examining the extent to which interdependence is a key factor compared with factors such as the technological intensity of an industry and the relative costs of cooperation. In the self-organisation model presented in section 4, we consider the possibility of lockin effects arising when pay-offs are not known ex ante (as they are in Axelrod's model) and where the sustainability of cooperation is not dependent on increasing numbers of new entrants (as they are in the Polya-Urn model).

In explicitly taking into account the interaction between individual agents, the selforganisation approach highlights the co-evolutionary dynamics of firm and industry innovation. Firms engage in innovation in order to bring about market changes that are favourable to their continued success and profitability. At the same time, the behaviour of other firms in the industry influences a firm's current behaviour. In this respect it is interesting to contrast Nelson's discussion of knowledge trading with that of von Hippel (see above). Like von Hippel, Nelson (1988) suggests that a more liberal attitude towards knowledge exchange is emerging, noting that "in some cases firms take positive actions to make their proprietary knowledge available to others" (Nelson, 1988, p. 318). However the strategic motivation suggested by Nelson is very different to that put forward by von Hippel. On the one hand, Nelson states that changing environmental conditions - increasing complexity and high rates of innovative change - are to some extent forcing firms to a adopt a more open position. In addition, he observes that diffusing certain types of know-how can be beneficial. If a firm's proprietary technology becomes the industry standard then it gains enormous advantages because all subsequent innovations that built on that standard are readily understood and absorbed by the standard-setter. In this way Nelson makes a link with work on systemic lock-in.

Discussions of interaction lead us to consider the creation of joint social capital within strategic alliances, the specificity of this capital and the effect of this specificity on opportunism. The absorption and synthesis of multiple technologies is not easy to manage or exploit. It is a creative act that invariably generates a fresh set of technical problems that need to be solved. Success depends not only on the technical competences of the individual firms making up a strategic alliance but also on inter-firm learning. 
Collaboration between firms holding complementary assets requires the creation and management of linkages between their respective competences and knowledge bases. This entails an understanding of what partners can reasonably expect of each other (their relative strengths and weaknesses) and how partners' competences can be synthesised together to create an innovative product. In effect, this represents the creation of social capital, an intermediate good that is used along with other inputs to produce R\&D. This social capital is highly specific to the particular alliance in which it is created. It is highly specialised, cumulatively created over time and thus premised on the establishment of stable, long-term relationships. In addition to economies due to learning-by-doing and learning-by-using, this social capital - embodied in the construction of inter-firm routines and experience - gives rise to economies due to learning-by-cooperating. The presence of these economies, the expected long-term returns to cooperation, and the sunk cost nature of these social capital investments, may be sufficient to keep in check short-term opportunism amongst alliance partners.

\subsubsection{Non-linearity of interactions}

The effects and benefits derived from inter-firm learning and cooperation are likely to be non-linear over time. There are a number of reasons for this. First, due to market and technological limitations, the opportunities of collaboration in a particular sector are not unrestricted. Second, one of the implications of mutual learning over the longer term is a reduction of dissimilarity between partners and an undermining of the stability of the alliance. With the depletion of these opportunities, cooperation becomes less attractive. Applying Kuhn's (1962) theory of scientific paradigms to the technological domain, Frenken and Verbart (1998) observe that the problem-solving capacity of a technology is influenced by the number of previous contributors to a technology. As the number of contributors increases in the initial phase of its history, so the problem-solving capacity of the network supporting that technology increases exponentially due to gains in the division of labour and benefits arising from new fields of application. There is, however, an upper limit to the problem-solving capacity of a user network. As a technology paradigm matures, so co-ordination costs start to outweigh the gains derived through further divisions of labour. The ability to identify and develop new fields of application is similarly limited and anomalies signal open questions that are considered to be beyond solution within the technology's framework. Consequently the growth of problem-solving capacity begins to slow to a standstill. Frenken and Verbart suggest that the functional form of the relationship between the problem-solving capacity of a technology and the number of contributors is likely to be sigmoid.

Turning to the relationship between learning benefits and the degree of differentiation between alliance members, resource-based theory emphasises that learning benefits are greatest in alliances containing firms that are highly dissimilar with respect to their resource portfolios. Yet one of the implications of mutual learning over the longer term 
is a reduction of dissimilarity between partners and, hence, an undermining of the stability of the alliance. Heterogeneity of firms within an alliance decreases because they become technologically closer through the very act of sharing their know-how. Dodgson notes that if firms "share knowledge over a longer period, then they will increasingly come to resemble one another with detrimental consequences for novelty and innovation" (Dodgson, 1996, p. 67). Since heterogeneity is a necessary precondition for spill-overs with high information content, increasing homogeneity makes further exchanges less attractive (there is less to be 'exchanged') leading to decreasing returns to cooperation. Consequently one would not expect the beneficial effects of mutual learning in a cooperative environment to increase linearly ad infinitum but, rather, to be bound from above. Depending on the particular form which this function takes, the relationship between returns and membership size will either be sigmoid or else an upper-bound log function consistent with a traditional diminishing returns-type argument.

\subsubsection{Emergence}

Multi-scale effects are likely to be present, with a second feedback loop existing between the emerging organisational structures observed in an industry and individual decisionmaking. If the returns to cooperative $R \& D$ conducted within an alliance are frequencydependent, i.e. returns depends on the share of firms engaged in an innovation alliance, then bandwagons can arise. If the number of cooperating firms is increasing, the gains to cooperative behaviour increase on average, making it more attractive for other firms to join an innovation alliance. One may reasonably expect to see a positive feedback between individual decisions to invest in collective knowledge production, the economic returns to each member of an alliance, and an increasingly open attitude towards further knowledge sharing. Alternatively, a negative feedback can arise if an increasing number of firms decide to leave their respective innovation alliances in order to innovate independently. Then the returns to cooperating will decline on average, reducing still further the incentive to belong to an innovation alliance.

Cooperative structures can emerge as an 'institution', where an institution is defined as an observed regularity in the behaviour and/or actions of individuals or groups when they encounter a similar set of circumstances. Once established, an institution has an important influence on individuals' expectations of the future, locking in the system to a stable long-run structure (Witt, 1987, p. 87). We have noted how the prediction of cooperative behaviour differs between transaction costs theory and resource-based theory. Transaction costs theory suggests alliances are unstable if assets are highly specific while resource-based theory proposes that, despite assets being highly specific, a strategic alliance will be stable provided the benefits are evenly distributed amongst the members. The self-organisational perspective emphasises that asset specificity and relative coordination costs can be outweighed by other factors, notably micro-macro 
interactions, which lead to the institutionalisation of cooperative or competitive behaviour.

\section{MODELLING THE SELF-ORGANISATION OF STRATEGIC ALLIANCES}

In order to further investigate the factors affecting the formation of horizontal $R \& D$ alliances in dynamic markets, we present a self-organisation model that builds on previous work by Pyka (1999). The model draws on Haken's synergetic approach (Haken, 1978) and is based on a Master-Equation algorithm (see Weidlich and Haag, 1983). The other notable feature of the model is its evolutionary character. Unlike more traditional neo-classical approaches, an optimisation calculus is no longer employed. Rather, the evolution of an alliance structure depends on the technological intensity of the industry, the relative costs of cooperation and competition, and the prevailing degree of cooperation.

The model contains a population of firms (agents) that collectively make up an industry. In every period, each firm must decide whether to 'join an innovation alliance' or else 'go it alone'. A firm that joins an alliance chooses to act cooperatively, voluntarily disclosing its existing (including newly acquired) know-how and exchanging this knowledge with other firms. This creates the basis for an informal innovation alliance in which knowledge is pooled. Alternatively, if a firm decides to act independently then it does not disclose its existing know-how and competes directly with all other firms. The need to exchange knowledge and access external knowledge sources increases when a firm can no longer reasonably expect to be successful through its own efforts. This is particularly true if the innovation process is characterised by increasing complexity and accelerating rate of change. In making their decisions, firms are strongly influenced by the choices of other firms within the same competitive environment. Hence one would expect strong bandwagon effects as decisions to act cooperatively are affected by the numbers of firms that already engage in cooperation.

Equilibrium in this model arises when the macro structure is stable. Changes in behaviour can still continue to occur at the individual micro level, however, since a macro equilibrium only implies that the rate of change from one behaviour to another is matched by an equal rate of change in the opposite direction. In this model the behaviour of interest is the choice between cooperative innovation through alliances versus competition based on individual R\&D. The model considers the probability of a transition from one type of behaviour to the other, i.e. from cooperative R\&D to competitive $R \& D$ strategies, or from competitive $R \& D$ to cooperative $R \& D$. The switch from one behaviour to another is described by 'individual transition rates'. These transition rates are the key aspect of a Master-Equation which describes the probability of 
an agent changing its behaviour. There are two conditions under which there is a high probability of a firm changing its behaviour. The first is when the size of the cooperative environment is growing. If the number of cooperating firms - and hence the returns to the external knowledge pool - is growing, the gains of cooperative behaviour increases, making it more attractive for other firms to join the strategic alliance. The second case occurs when the opposite conditions prevail. There is a high probability of a firm changing its behaviour when the size of the cooperative environment is declining. If the environment is initially cooperative but there is an increasing number of firms who decide to leave the alliance(s) and to innovate independently, then returns to the external knowledge pool will decline, further reducing the attractiveness of belonging to an alliance. To summarise, the probability of switching to cooperative behaviour increases as an alliance grows in size while the probability of switching to competitive behaviour increases as an alliance declines in size. This mutual learning process reflects the first characteristic of self-organising systems: local interaction.

The behavioural rule followed by firms in our model is very simple. Each firm considers the structure of the innovation environment by taking into account whether other firms are currently cooperating or competing, and the relative costs of setting up an alliance versus the costs of conducting in-house R\&D. In marked contrast to transaction cost and resource-based models, this avoids placing high demands on the ability of firms to initially gather information and estimate the skills and competences of potential partners and/or the long-term gains of cooperation. The transition rate of competitive $(c)$ to cooperative (co) behaviour $p_{c \rightarrow c o}$ in the model depends on two components, (i) the positive returns associated with alliance size and (ii) the costs of establishing and coordinating a strategic alliance. These are captured respectively in the left- and righthand terms of equation (1).

$$
p_{c \rightarrow c o}(x)=\alpha_{1} \cdot \exp (\beta \cdot x)-\alpha_{2} /[1+\exp (x)] ; \quad x \in\{0,1\}, \alpha_{i} \in\{0,1\}, \beta>0
$$

The size of an alliance is described along a discrete state space $x$ giving the particular distribution of cooperative firms and non-cooperative firms. $x=0$ when there is a purely competitive environment, $x=1$ if all firms participate in a strategic alliance, and $x=0.5$ when there is an equal distribution of cooperative and competitive firms. $\alpha_{i}$ is a frequency parameter and $\beta$ is the degree of technological intensity.

The exponential formulation of the transition rates captures the second characteristic of self-organising systems: non-linearity giving rise to a positive feedback gains that are bounded from above. Positive returns associated with alliance size arise from the beneficial effects of cooperative mutual learning discussed in section 3 . As an alliance expands, so the returns to mutual learning increase over time. However, there are two reasons why one would not expect these positive returns to be linearly increasing in the long run. First, the performance improvements that can be gained from continued development of a particular technology, and the range of its potential application, are not 
unrestricted. With the depletion of technological opportunities, the returns to continued investment in this technology, and the particular structure in which technological innovation is coordinated, becomes less attractive. Second, following Dodgson (1996), the heterogeneity of firms within an alliance may decrease over the long-run through the very act of sharing information and know-how. If, as resource-based theory argues, heterogeneity is a necessary condition for strategic alliance formation because spill-overs have a high information content, then increasing homogeneity of the members of an alliance makes further exchanges less attractive (there is less to be 'exchanged') leading to decreasing returns to alliance membership.

The costs of coordinating innovation within a strategic alliance are also likely to be nonlinear over the long-run. This is captured by the frequency parameter $\alpha_{2}$, with positive cooperation costs that have an upper bound. As discussed in section 3, firms typically experience difficulties in drawing on the external knowledge sources of their partners in the initial phase of an alliance and the knowledge flows within an alliance are not easily used for a firm's own purposes. However, partners build social capital over time and develop understandings that are translated into routines and experience. These routines and experience can in turn make future cooperation with additional partners easier to facilitate. Through learning-by-cooperating the marginal cost of additional cooperative activity will begin to decrease. In terms of alliance size, this learning-by-cooperating effect can lead to economies of scale, enabling larger sustainable alliances to form.

Turning to the transition rate of cooperative (co) to competitive (c) behaviour $p_{c o \rightarrow c}$, this similarly depends two factors. These are (i) the returns associated with alliance size and (ii) the costs of establishing and coordinating an independent in-house R\&D facility.

These are captured respectively in two terms of equation (2).

$$
p_{c o \rightarrow c}(x)=\alpha_{1} \cdot \exp (-\beta \cdot x)-\alpha_{3} /[1+\exp (x)] ; \quad x \in\{0,1\}, \alpha_{i} \in\{0,1\}, \beta>0
$$

We observe that there is no reason to assume that the costs associated with each strategy will be identical. Indeed, as observed in section 3, an important issue driving much of the empirical debate concerns the costs of establishing and coordinating an independent inhouse $\mathrm{R} \& \mathrm{D}$ facility vis-à-vis the costs of establishing and coordinating a strategic innovation alliance. If the relative costs of pursuing each strategy differ then the transition rates will not be perfectly symmetric with respect to switches between competitive and cooperative behaviours.

Ceteris paribus, the restricted technological opportunities of a specific technological path will tend to reduce the dynamics of technological evolution, with similar effects on the importance of cooperation and mutual learning. However, as discussed in section 3, technological evolution is characterised by mutual interdependencies between different 
core technologies. New technological opportunities can be created through the fusion of, what were previously thought of as unrelated, knowledge fields. The other key source of interaction discussed in section 2 is between technological and scientific knowledge bases, developments in each frequently having impacts on the other. These cross fertilisations sustain the heterogeneity of technological approaches across firms in a dynamic perspective and correspond to the first feature of self-organising systems: thermodynamic openness. The particular choice of exponential transition rates allows to overcome the restrictions of exploiting intensive technological opportunities only by also exploring new extensive technological opportunities emerging within a technology intensive environment. By this, the system is prevented from falling into a local equilibrium and reaching stasis.

Using the transition rates of equations (1) and (2) we form a Master-Equation. The Master-Equation is used to compute the probability of a change from one type of behaviour to another (i.e. from competition to cooperation or vice-versa) at each moment in time, and thereby determine the change in probability of a strategic alliance of a certain size $\frac{d P(x ; t)}{d t}$ existing in each time period. The Master-Equation for the system of evolving strategic alliances is a stochastic differential equation.

$$
\begin{aligned}
\frac{d P(x ; t)}{d t} & =p_{c \rightarrow c o}(x+\varepsilon) \cdot P(x-\varepsilon ; t)+p_{c o \rightarrow c}(x+\varepsilon) \cdot P(x+\varepsilon ; t) \\
& -p_{c \rightarrow c o}(x) \cdot P(x ; t)-p_{c o \rightarrow c}(x) \cdot P(x ; t)
\end{aligned}
$$

The master-equation can be thought of as an accounting device that provides information on the probability of a specific configuration $x$ occurring at time $t$. This probability can change due to four different probability fluxes describing movements out and into a specific state. The above two terms with a positive sign capture the positive effect on state $x$ arising from a change in probability fluxes from a neighbouring state $(x-\varepsilon$ or $x+\varepsilon)$. Changes in these aggregate probability fluxes are driven by movements of individual firms between neighbouring states. These arise whenever firms decide to change their behaviour and either join an strategic alliance $(x-\varepsilon)$ or else leave an alliance and 'go it alone' $(x+\varepsilon)$. In either case, the probability that a specific configuration $x$ (distribution of cooperative and competitive firms) will dominate the system increases as a consequence of a flux from one behavioural state to another. The below two terms with a negative sign capture the negative impact of a probability flux, due to departing firms who have changed their behaviour, on the original behavioural state. Changes in firm behaviour decrease this probability, raising the probability of attraction to a neighbouring state. 


\section{RESULTS}

\subsection{Mean field analysis}

As a first approximation, we formally analyse a simple version of the model using the Mean Field method. The aim here is to obtain a qualitative appreciation of the behaviour of the model prior to simulation. This is a useful means of focusing the simulation experiments that are subsequently conducted on the model. The limits of applicability of the method are an advanced topic in statistical physics and a full discussion of these is beyond the scope of the current paper. However, even in those case cases where its predictions are quantitatively inaccurate, the method is good enough to predict phase transitions and some dynamical properties in their neighbourhood (Brout, 1965; Weisbuch et al., 2000).

The Mean Field method replaces randomly fluctuating quantities by their average, thus neglecting their fluctuations. In this case we apply the method to a simple version of the model where the costs of cooperative $R \& D$ are equal to the costs of in-house R\&D for all firms. Making $\alpha_{2}=\alpha_{3}$, we analyse the state space $x$ describing the distribution of cooperative firms $n_{1}$ and non-cooperative firms $n_{2}$. For each value of $x$ the share of cooperative and non-cooperative firms is computed using the formula $x=2\left(n_{1}-0.5\right)=2(0.5$ $n_{2}$ ). The mean value is derived by summing the net rate of behavioural changes $\dot{x}=n_{2} \cdot p_{c o \rightarrow c}(x)-n_{1} \cdot p_{c \rightarrow c o}(x)$. The Mean Field approximation consists of replacing $\dot{x}$ by the expected value $<\mathrm{x}>$, thereby transforming the stochastic differential equation into a deterministic differential equation - the so-called mean-value equation ${ }^{2}$.

$$
\langle x\rangle=\alpha_{1} \cdot \sinh (\beta \cdot x)-x \cdot[\cosh (\beta x)]+\frac{\alpha_{2}}{1+\exp (x)}
$$

\footnotetext{
${ }^{2}$ See Weidlich/Haag (1983). The state space $x$ describes the particular distribution of cooperative firms $n_{l}$ and non-cooperative firms $n_{2}$. For each value of $x$ it is straightforward to compute the share of cooperative and non-cooperative firms respectively, following the formula: $x=2\left(n_{1}-0.5\right)=2\left(0.5-n_{2}\right)$. Using this, we derive the mean-value equation by summing up the net rate of behavioural changes $\dot{x}=n_{2} \cdot p_{c o \rightarrow c}(x)-n_{1} \cdot p_{c \rightarrow c o}(x)$. Accordingly, we get the following equation: $\dot{x}=\left(0.5-\frac{x}{2}\right) \cdot\left\{\alpha_{1} \cdot \exp (\beta x)-\alpha_{2} /[1+\exp (x)]\right\}-\left(\frac{x}{2}+0.5\right) \cdot\left\{\alpha_{1} \cdot \exp [-(\beta x)]-\alpha_{3} /[1+\exp (x)]\right\} \quad$ leading to $\dot{x}=\alpha_{1} \cdot \sinh (\beta x)-x \cdot \alpha_{1} \cdot \cosh (\beta x)+\frac{\frac{x}{2} \alpha_{3}+0.5 \alpha_{3}+0.5 \alpha_{2}-\frac{x}{2} \alpha_{2}}{1+\exp (x)}$. By putting $\alpha_{2}=\alpha_{3}$ we derive equation
} (4) above. 
Using the Mean Field method we are able to identify three possible equilibrium states in this system; (i) coexistence of cooperative and competitive behaviour, (ii) dominance by cooperative behaviour and (iii) dominance by competitive behaviour. Moreover, it is found that convergence to a particular equilibrium state is sensitive to changes in the value of the technology intensity parameter $(\beta)$. Indeed, as the bifurcation diagram in figure 1 shows, the Mean Field method predicts the system undergoes a phase transition at $\beta=1$. For $\beta$ values below 1 , the equilibrium solution has a mean distribution of 0.5 between cooperative and competitive firms. This corresponds to a state of maximum entropy, as discussed in section 2. We call this a disorganised regime since one cannot predict ex ante whether a firm picked at random will be cooperative or competitive in behaviour.

By contrast, the model is characterised by ordered regimes for values of $\beta$ greater than 1 . These ordered regimes arise from initially disordered conditions. It is interesting to note that the system has two alternative development paths when $\beta>1$. The system may either converge to an ordered regime of cooperative R\&D or, alternatively, an ordered regime of competitive R\&D. This supports the earlier discussion regarding the emergence of very different institutions for innovation between within sectors which are otherwise very similar.

The existence of a phase transition highlights the fourth characteristic of self-organising systems: the emergence of discrete and highly differentiated macro patterns that are due to small changes in micro behaviour. In this case, significantly different industry structures arise at higher technological intensities where $\beta>1$ (i.e. fast pace of technological progress, cross-fertilisation effects, inputs from the scientific realm etc.). Below a particular threshold, cooperative and competitive behaviours can co-exist in comparatively egalitarian distributions. However, above this threshold the system tends towards end states in which one or other behaviour dominates.

Unfortunately the limitations of the Mean Field method are such that we cannot investigate the way in which small fluctuations in behaviour and in initial conditions affect the final outcome of the system when $\beta>1$. In addition to examining the way in which the system's development path is affected by random events, we wish to explore the impact of differences in the relative cost of collaboration and competition as well as the degree of technological intensity. In order to conduct this analysis we next turn to the results generated by a series of simulation exercises carried out on the model. 


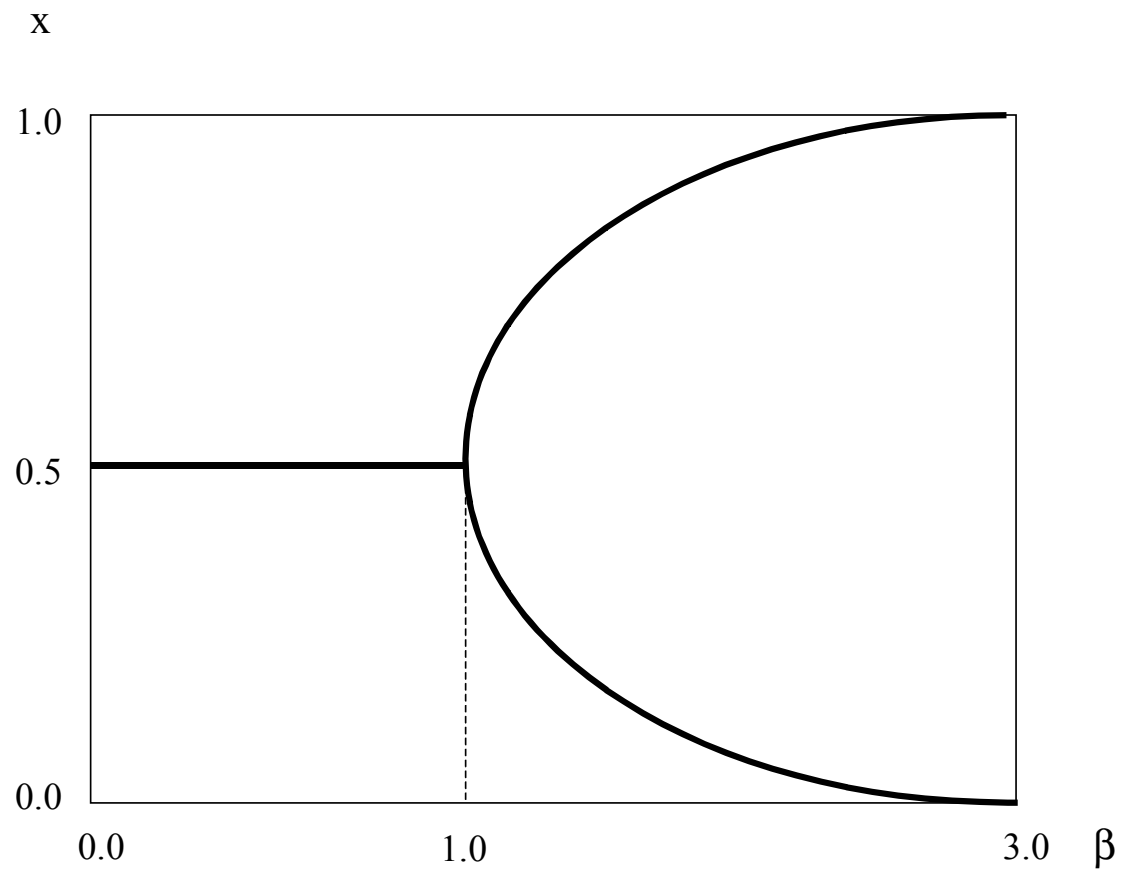

Figure 1. The order/disorder transition in $\beta$

\subsection{SIMULATION ANALYSIS}

Unfortunately, given its highly non-linear character, traditional analytic methods do not assist the investigation of this model's properties. The mean-value approach only provides a good approximation in cases where the system has not undergone a phase transition. However, once a system has undergone a phase transition, the approach can generate unlikely results ${ }^{3}$. Consequently one is forced to turn to computer-based numerical techniques in order to obtain an accurate description of the system's behaviour.

Before discussing the simulation results, some preliminary remarks need to be made regarding the reported simulation exercises. The model was run for 2,000 periods for each simulation. The frequency parameters $\alpha_{1}$ and $\alpha_{2}$ were fixed at 0.25 and 0.01

\footnotetext{
${ }^{3}$ See Erdmann (1993).
} 
respectively for all simulation runs. Finally, the initial distribution is $P(x=0 ; 1)=0.5$, i.e. there was an equal probability of cooperative and competing firms at the outset of each simulation run. In the first scenario, we explore the behaviour of the system when technological intensity is relatively low $(\beta=0.8)$. Figure 2 illustrates the type of probability distributions $P(x)$ that emerge in order to meet a certain alliance size $x$ over time $t$. It was found that the system tends to converge to a uni-modal stationary solution in which the population of firms is divided between two equivalently sized groups, one acting cooperatively and the other competitively. Thus, in a sector in which technological change is not a key factor, the existence of an upper bound to alliance benefits prevents the formation of larger alliances. Technological opportunities are quickly depleted and the low degree of heterogeneity amongst firms means the benefits to strategic alliances are low over the course of time.

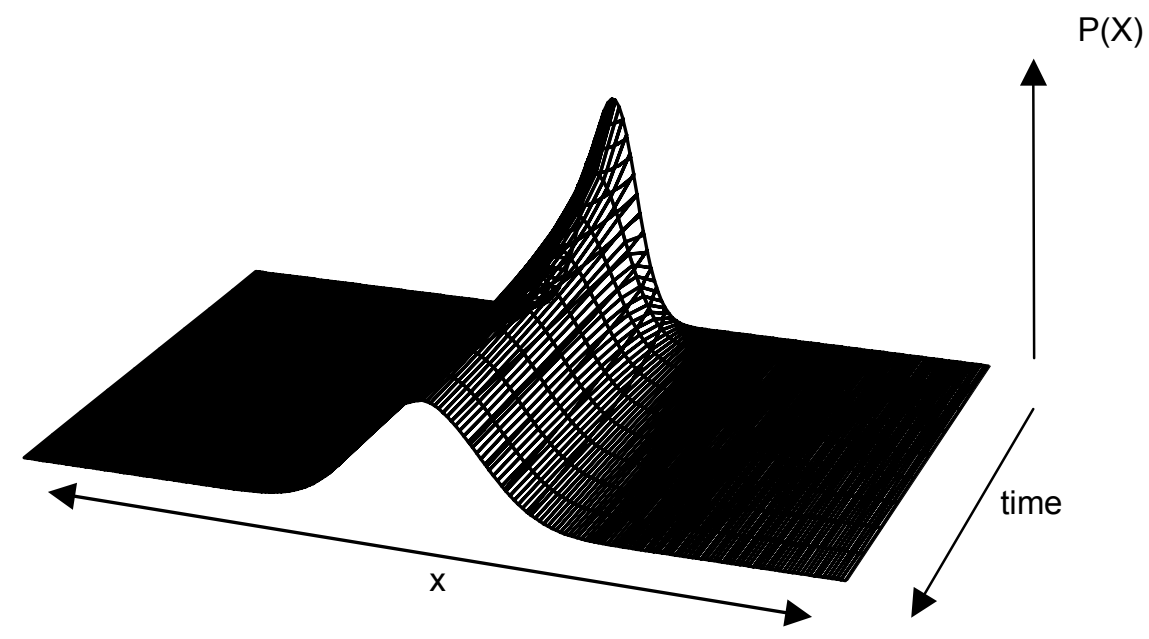

Figure 2. System development with technological intensity $\beta<1$

Figure 3 illustrates a second scenario where technological intensity $\beta=1$. This approaches the critical value identified by our earlier investigation of the mean-value equation. While the median of the end state is the same as the first scenario, it takes longer for the system to reach a stationary distribution. What is more, the final distribution is considerably different to that which emerges under the first scenario (Figure 2). The distribution that emerges under the second scenario contains two local maxima, one slightly biased on the (left) cooperative side and another that is more marked towards the (right) competitive side. Thus the system is beginning to shows signs of an emergent bimodal structure, with larger cooperative and competitive clusters beginning to self-organise. 


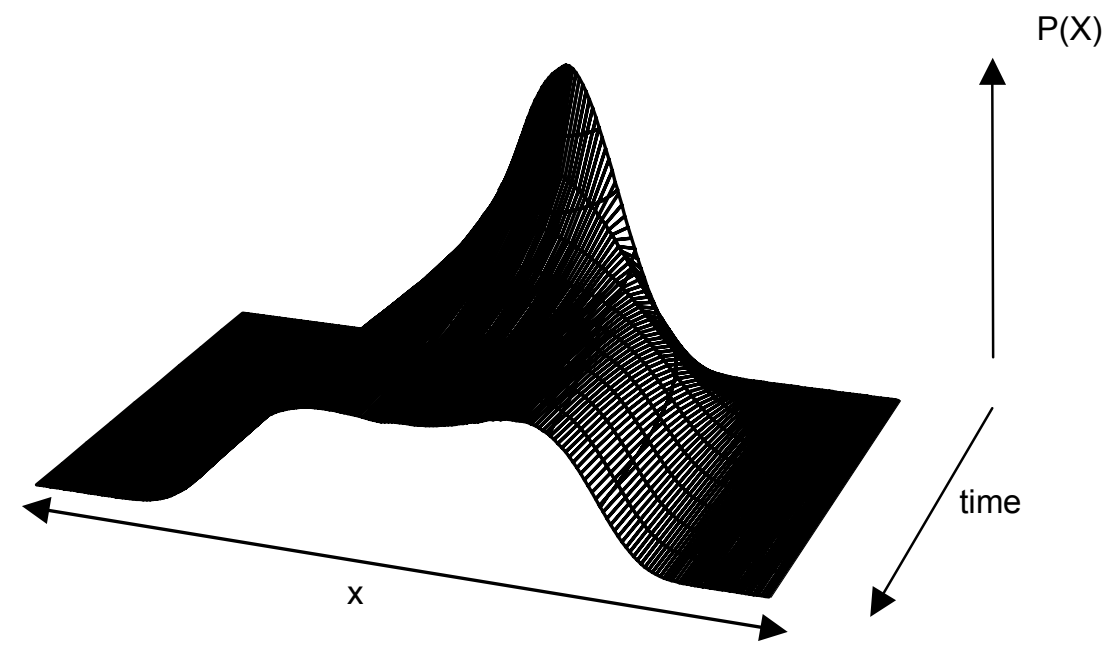

Figure 3. System development with technological intensity $\beta=1$

Figure 4 illustrates a third scenario in which there is a high technological intensity, $\beta=$ 1.25. The end state that emerges at this level of technological intensity differs significantly to the previous cases. Here the system undergoes a bifurcation such that dominance by one type of behaviour - either competition or cooperation through strategic alliances - is the most probable end state. It is not possible to predict ex-ante which of these behaviours will dominate because convergence to one or the other end state critically depends on fluctuations that occur during the phase-transition. Despite the exploitation of intensive technological opportunities, technology maintains its importance in time via the exploration of extensive technological opportunities, making it attractive for firms either to stick to a competitive strategy or else create large strategic alliances. 


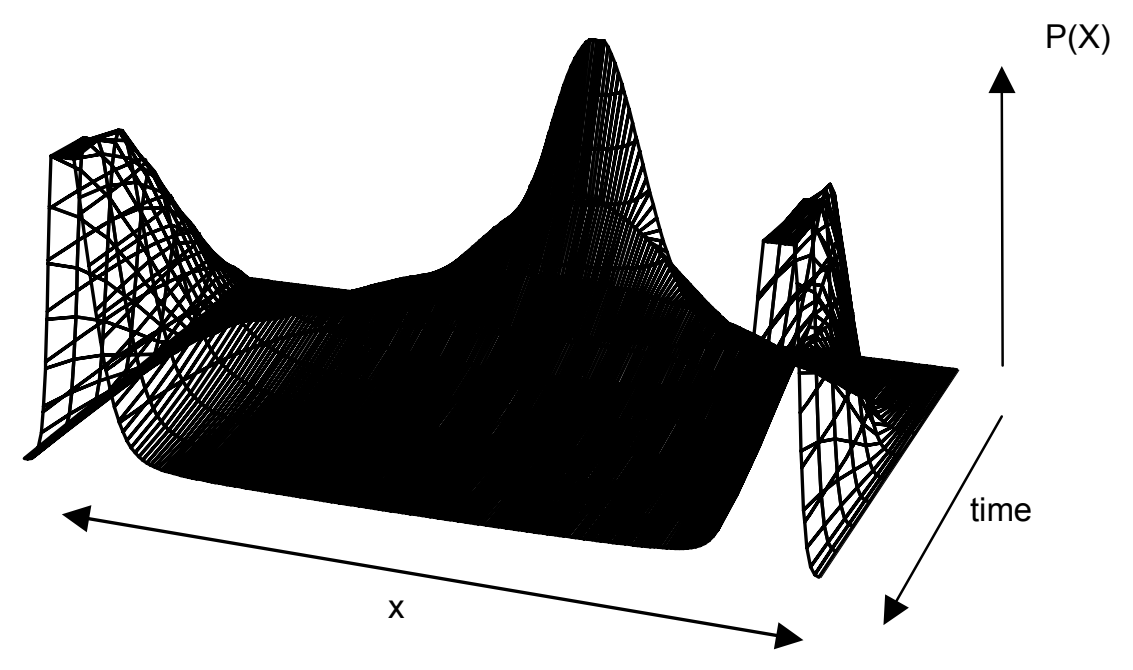

Figure 4. System development with technological intensity $\beta>1$

This type of solution has been observed in empirical case studies conducted by Eliasson (1995). For example, innovation alliances play a dominant role in sectors such as semiconductors and biotechnology-based combinatorial chemistry. These fields of knowledge production are characterised by significant technological dynamics and by firms that are highly inter-dependent. Firms are apparently unable to be individually self-sufficient in the acquisition of critical complementary knowledge, participation in informal alliances being a decisive mechanism through which firms seek to maintain themselves at the leading edge of the technological frontier. Yet this form of cooperative know-how exchange is more or less absent in sectors that are equally technologically dynamic and have ostensibly similar characteristics. In chemistry, for example, we see an industry structure in which firms are more or less self-sufficient in the production of critical complementary knowledge through in-house R\&D activities.

The self-organisation model has a number of interesting properties. First, the results accord with von Hippel's empirical observations regarding the willingness of firms to engage in informal knowledge trading. However the model is able to generate these without making strong assumptions (as von Hippel did) about the abilities of individual agents to collect, evaluate and compare all internally- and externally-held information. In this model agents' decisions on whether to cooperate in strategic alliances depend upon the size of the cooperative environment, whether this is growing or declining, and the costs of cooperation. If the number of cooperating firms - and hence the returns to the external knowledge pool - is growing, the gains of cooperative behaviour increases, making it more attractive for other firms to join the strategic alliance. 
This leads us to a second property of the model. Multi-scale effects arise due to local interactions between agents generate cooperative and competitive aggregate structures which in turn affect individual decision-making. Hence stable and ordered paths of change emerge as the (partly) unintentional outcome of interactions between individual agents. This result nicely illustrates Nelson's point that the basis of cooperative innovation is not only to be found in strategic decision-making but is strongly influenced by the industrial environment in which firms operate. Finally, the model contains multiple possible end-states. Convergence to one or other end state depends on small differences that occur at crucial points in time. This emphasises the point made by Silverberg et al. regarding the nature of uncertainty in real historical time (also see Arthur (1989) and David (1985) on this point). Decisions in our model are frequency-dependent and so it is impossible to predict ex ante which type of behaviour will eventually come to dominate. Given this interdependence between firms' strategic choices, bandwagon effects can quickly spread as a result of previous changes in behaviour. As a consequence, selection of one or other end state is non-ergodic and highly sensitive to the way in which the sequence of decisions are built up.

\section{CONCLUSIONS}

The model presented in the paper offers a promising avenue for the study of strategic alliances. To begin with, the model is founded on a general framework of dynamic systems, a framework under which a largely fragmented body of research can be drawn together. Second, the self-organisation framework offers a set of modelling techniques capable of generating new insights. In this paper the focus has been the rationale for cooperative behaviour by firms within horizontally structured strategic alliances. Three key factors have been considered: the relative coordination costs of cooperation and competition, the rate of technological innovation in the sector, and the institutional history of the industry.

Transferring the core concepts and modelling methods of self-organisation theory from natural to social science domains is a non-trivial task and must be handled with care. For this reason the paper began by identifying the four key principles of self-organisation local interaction, non-linearity, thermodynamic openness and emergence - and thereafter proceeded to identify a set of stylised facts of inter-firm cooperation within formal and informal strategic alliances that can be brought together under the self-organisation rubric. This prepared the way for the formal model of self-organising strategic alliances presented in section 4 of the paper.

Turning to the formal findings of the paper, the experiments conducted on the model offer a number of interesting insights into the dynamics of strategic alliances. First, in 
accordance with von Hippel's empirical observations, cooperative structures can emerge in which individual firms willingly engage in informal knowledge trading. However, unlike von Hippel, the model can generate these results without recourse to strong assumptions regarding the information processing abilities of individual agents. In our model individuals learn by reinforcing the actions that were most profitable in the past. The behavioural rule considers the network externality associated with cooperation and competition, and the relative costs of establishing an alliance or conducting in-house R\&D.

Turning to the three factors considered in the model, it is found that, ceteris paribus, the relative costs of strategic alliances and in-house R\&D only have a bearing in the limit. Only under exceptional circumstances will the relative costs of coordination lead to a purely competitive distribution $(\mathrm{x}=0)$ or a purely cooperative distribution $(\mathrm{x}=1)$. The second factor examined, the technological intensity $(\beta)$ of the sector, if found to have a far more significant effect on the final outcome however. In both the mean field and simulation exercises a bifurcation point is established at $\beta=1$. For $\beta$ values below 1 there is a disorganised regime with maximum entropy $(x=0.5)$. Ordered regimes in which competitive or cooperative distributions are stable occur when $\beta$ is greater than 1 .

Finally, the model contributes to the current debate on strategic alliances by highlighting the importance of micro-macro feedbacks between individuals' decision-making and emergent institutional environments. The presence of order in innovation is very dependent on, and sensitive to, the way in which agents react to their previous experience. Convergence to competitive or cooperative equilibria depends on the sequence of decisions that are built up over time. At the same time, the mutual interdependence of individual choices means that payoffs are frequency dependent. This can readily lead to multi-scale bandwagon effects because interactions between agents generate ordered structures that in turn influence future decisions. The net result is a coevolution of innovation structure and profitability within an industry. Yet one cannot predict ex ante whether a competitive or a cooperative structure will emerge. Alternative outcomes can emerge in different industries even though firms within those industries face similar transaction costs, levels of technological uncertainty and asset specificity. 


\section{Bibliography}

Abernathy, W.J. and Utterback, J.M., 1975, A dynamic model of product and process innovation, Omega, 3, pp.639-656.

Anderson, E. and Gatignon, H., 1986, Modes of foreign entry: a transactions cost analysis and propositions, Journal of International Business Studies, 17 (3), pp.1-26.

Arora, A., and Gambardella, A., 1994, The changing technology of technological change: general and abstract knowledge and the division of innovative labour, Research Policy, 23 , pp.523-532.

Arthur, W.B., 1989, Competing technologies, increasing returns and lock-in by historical events", Economic Journal, 99, pp.116-131.

Arthur, W.B., Ermoliev, Y. M. and Kaniovski, Y.M., 1985, Strong laws for a class of path-dependent urn processes, in V. Arkin, A. Shirayayev and R. Wets (eds.), Proceedings of the International Conference on Stochastic Optimization, Kiev 1984, Springer-Verlag: Berlin, Heidelberg, New York.

Arthur, W.B., Ermoliev, Y. M. and Kaniovski, Y.M., 1987, Path dependent processes and the emergence of macrostructure, European Journal of Operational Research, 30, pp. 294-303.

Artz, K.W. and Brush, T.H., 2000, Asset specificity, uncertainty and relational norms: an examination of coordination costs in collaborative strategic alliances, Journal of Economic Behavior and Organization, 41, pp.337-362.

Axelrod, R., 1980, Effective choice in prisoner's dilemma, Journal of Conflict Resolution, 24, pp.3-25.

Axelrod, R., 1981, The emergence of cooperation among egoists, American political Science Review, 75, pp.306-318.

Banerji, K. and Sambharya, R.B., 1998, Effect of network organisation on alliance formation: a study of Japanese automobile ancillary industry, Journal of International Management, 4(1), pp.41-57.

Bassanini, A. and Dosi, G., 1998, Competing technologies, international diffusion and the rate of convergence to a stable market structure", IIASA Interim Report, IR-98-012, Laxenburg: IIASA.

Barney, J., 1991, Firm resources and sustained competitive advantage, Journal of Management, 17, pp.99-120. 
Basalla, G., 1988, The Evolution of Technology, Cambridge University Press: Cambridge.

Beamish, P. and Banks, J., 1987, Equity joint venture and theory of multinational enterprise, Journal of International Business Studies, 18 (2), pp.1-16.

v. Bertalanffy, L., 1968, The Quest for a General System Theory, George Braziller: New York.

Brout, E., 1965, Phase Transitions, Benjamin: New York.

Cavantio, J.L., 1992, The total cost/value model for supply chain competitiveness, Journal of Business Logistics, 13, pp.285-301.

Cohen, W.M. and Levinthal, D.A., 1990, Absorptive capacity: a new perspective on learning and innovation, Administrative Science Quarterly, 35, pp.128-152.

Crocker, K.J. and Masten, S., 1991, Pretia ex machina? prices and process in long-term contracts, Journal of Law and Economics, 34, pp.69-99.

Crutchfield, J. P., 1994, Is anything ever new?, in G. Cowan, D. Pines, and D. Melsner (eds.), SFI studies in the sciences of complexity XIX, Addison-Wesley: Massachusetts.

Dalle, J.M., 1997, Heterogeneity versus externalities in technological competitions, Journal of Evolutionary Economics, 7, pp.395-413.

David, P., 1985, Clio and the economics of QWERTY, American Economic Review Papers and Proceedings, 75, pp.332-336.

Deeds, D.L. and Hill, C.W.L., 1996, Strategic alliances and the rate of new product development: an empirical study of entrepreneurial biotechnology firms, Journal of Business Venturing, 11, pp.41-55.

Dickson, P.H. and Weaver, K.M., 1997, Environmental determinants and individual-level moderators of alliance use, Academy of Management Journal, 40, pp. 404-425.

Dodgson, M., 1996, Learning, trust and inter-firm linkages: some theoretical associations, in R. Coombs, a. Richards, P.P. Saviotti and V. Walsh (eds.), Technological Collaboration: The Dynamics of Cooperation in Industrial Innovation, Edward Elgar: Cheltenham.

Dosi, G., 1988, Sources, procedures, and microeconomic effects of innovation, Journal of Economic Literature, 26, pp.1120-1171.

Eigen, M., 1971, Self-organisation of matter and the evolution of biological micromolecules, Naturwissenschaften, 58, pp.465-522. 
Eliasson, G., 1995, General purpose technologies, industrial competence and economic growth - with special emphasis on the diffusion of advanced methods of integrated production, Working Paper, Royal Institute of Technology, Stockholm.

Erdmann, G., 1993, Elemente einer Evolutorischen Innovationstheorie, J. C. B. Mohr: Tübingen.

Freeman, C., 1974, The Economics of Industrial Innovation, Penguin: Hermondsworth.

Frenken, K. and Verbart, O., 1998, Simulating paradigm shifts using a lock-in model, in P.Ahreweiler and N.Gilbert (eds.), Computer Simulation in Science and Technology Studies, Springer-Verlag: Berlin, Heidelberg, New York.

Forrest, S., and Jones, T., 1994, Modeling complex adaptive systems with echo, in R. J. Stoner and X. H. Yu (eds.), Complex Systems: Mechanisms of Adaptation, IOS Press: Amsterdam.

Gierer, G., 1981, Socio-economic inequalities: effects of self-enhancement, depletion and redistribution, Jahrbücher für Nationalökonomie und Statistik, Vol. 196, pp.309-331.

Hagedoorn, J., 1993, Understanding the rationale of strategic technology partnering: inter-organizational modes of cooperation and sectoral differences, Strategic Management Journal, 14, pp.371-385.

Håkansson H. and Johanson, J., 1988, Formal and informal cooperation strategies in international industrial networks, in F. J. Contractor and P. Lorange (eds.), Cooperative Strategies in International Business, Lexington Books: Lexington, MA., pp. 369-379.

Haken, H., 1978, Synergetik: Eine Einführung: Nichtgleichgewichtige Phasenübergänge und Selbstorganisation in Physik, Chemie und Biologie, Springer-Verlag: Berlin, Heidelberg, New York.

Hansen, E.L., 1995, Entrepreneurial networks and new organisation growth, Entrepreneurship: Theory and Practice, 19 (4), pp.7-19.

Harrigan, K.R., 1985, Strategies for Joint Ventures, Lexington Books: Lexington, MA.

Heide, J.B. and Miner, A.S., 1992, The shadow of the future: effects of anticipated interaction and frequency of contact on buyer-seller cooperation, Academy of Management Journal, 35, pp.265-291.

Hennart, J.-F., 1988, A transaction cost theory of joint ventures, Strategic Management Journal, 9, pp.361-374.

Hill, R.C. and Hellriegel, D., 1994, Critical contingencies in joint venture management: some lessons from managers, Organization Science, 5, pp.594-607. 
v. Hippel, E., 1989, Cooperation between rivals: informal know-how trading, in B. Carlsson (ed.), Industrial Dynamics, Kluwer: Doordrecht.

Hite, J.L. and Hesterley, W.S., 2001, The evolution of firm networks: from emergence to early growth of the firm, Strategic Management Journal, 22, pp.275-286.

Ibarra, H., 1992, Structural alignments, individual strategies, and managerial action: elements towards a network theory of getting things done, in N. Nohria and R.Eccles (eds.), Networks and Organizations: Structure, Form and Action, Harvard Business School Press, Boston, MA.

Jones, G.R. and Hill, C.W.L., 1988, Transaction costs analysis of strategy-structure choice, Strategic Management Journal, 9, pp.159-172.

Katz, M., and Shapiro, C., 1985, Network externalities, competition and compatibility, American Economic Review, 75, pp.424-440.

Kawata, M. and Toquenaga, Y., 1994, Artificial individuals and global patterns, Trends in Ecology and Evolution, 9, pp.417-421.

Klein, B., Crawford, R., Alchian, A., 1978, Vertical integration, appropriable rents, and the competitive contracting process, Journal of Law and Economics, 21, pp.297-326.

Kline, S.J. and Rosenberg, N., 1986, An overview of innovation, in The Positive Sum Strategy: Harnessing Technology for Economic Growth, R. Landau and N. Rosenberg (eds.), National Academic Press: Washington D.C.

Kodama, F., 1996, Emerging Patterns of Innovation: Sources of Japan's Technological Edge, Harvard Business School Press: Boston, MA.

Kogut, B., 1988, Joint ventures: theoretical and empirical perspectives, Strategic Management Journal, 9, pp.319-332.

Kranton, R., 1996, The formation of cooperative relationships, The Journal of Law, Economics and Organization, 12, pp.214-233.

Kuhn, T.S., 1962, The Structure of Scientific Revolutions, University of Chicago Press: Chicago.

Kydland, F.E. and Prescott, E.C., 1982, Time to build and aggregate fluctuations, Econometrica, 50, pp.1345-1370.

Larson, A.L. and Starr, J.A., 1993, A network model of organization formation, Entrepreneurship: Theory and Practice, 17 (2), pp.5-15. 
Lundvall, B-Å, 1992, National Systems of Innovation: Towards a Theory of Innovation and Interactive Learning, Pinter: London.

Lundvall, B-Å. and Johnson, B., 1994, The learning economy, Journal of Industry Studies, 1(2), pp.23-42.

Lyons, T.F., Krachenberg, A.R. and Henke, J.W., 1990, Mixed motive marriages: whats next for buyer-supplier relations?, Sloan Management Review, 3, pp.29-36.

Madhok, A., 1997, Cost, value and foreign market entry mode: the transaction and the firm, Strategic Management Journal, 18, pp.39-61.

Masten, S.E., 1984, The organization of production: evidence from the aerospace industry, Journal of Law and Economics, 27, 403-417.

Mokyr, J., 1990, The Lever of Riches, Oxford University Press: Oxford.

Monteverde, K. and Teece, D.J., 1982, Supplier switching costs and vertical integration in the automobile industry, The Bell Journal of Economics, 13, pp.206-213.

Mowery, D.C., Oxley, J.E. and Silverman, B.S., 1998, Technological overlap and interfirm cooperation: implications for the resource-based view of the firm, Research Policy, 27, pp.507-523.

Nelson, C. and Plosser, C., 1982, Trends and random walks in macroeconomic time series: Some evidence and implications, Journal of Monetary Economics, 10, pp.139167.

Nelson, R.R., and Winter, S.G., 1982, An Evolutionary Theory of Economic Change, Harvard University Press: Boston, MA.

Nelson, R. R., 1988, Institutions supporting technological change in the United States, in G. Dosi, C. Freeman, R. Nelson, G. Silverberg and L. Soete (eds.), Technical Change and Economic Theory, Pinter Publishers: London.

Nicolis, G. and Prigogine, I., 1977, Self-organisation in Non-Equilibrium Systems, Wiley Interscience: New York.

Nicolis, G., and Prigogine, I., 1989, Exploring complexity, W. H. Freeman: New York.

Noordeweir, T.G., John, G. and Nevin, J.R., 1990, Performance outcomes of purchasing arrangements in industrial buyer-vendor relationships, Journal of Marketing, 54, pp.8093.

Parkhe, A., 1993, Strategic alliance structuring: a game theoretic and transaction cost examination of interfirm cooperation, Academy of Management Journal, 36, pp.794-829. 
Penrose, E., 1959, The Theory of the Growth of the Firm, Blackwell: Oxford.

Peteraf, M.A., 1993, The cornerstones of competitive advantage: a resource-based view, Strategic Management Journal, 14, pp.179-191.

Powell, W., Koput, K. and Smith-Doerr, L., 1996, Interorganization collaboration and the locus of innovation: networks of learning in biotechnology, Administrative Science Quarterly, 41, pp.116-145.

Prahalad, C.K. and Hamel, G., 1990, The core competence of the corporation, Harvard Business Review, May-June, pp.79-91.

Prigogine, I., 1976, Order through fluctuation: self-organisation and social system, in Evolution and Consciousness, E. Jantsch and C.H. Waddington, (eds.), Addison-Wesley: New York.

Prigogine, I., 1980, From Being to Becoming: Time and Complexity in the Physical Sciences, Freeman: San Francisco.

Prigogine, I. and Stengers, I., 1984, Order out of Chaos, New York.

Pyka, A., 1999, Der kollektive Innovationsprozess - Eine theoretische Analyse informeller Netzwerke und absorptiver Fähigkeiten, Duncker and Humblot: Berlin.

Ring, P.M. and v.d. Ven, A., 1992, Structuring cooperative relationships between organizations, Strategic Management Journal, 13, pp.483-498.

Romer, P., 1990, Endogenous technological progress, Journal of Political Economy, 98, pp.71-102.

Rosenberg, N., 1982, Inside the Black Box: Technology and Economics, Cambridge University Press: Cambridge.

Rosenberg, N., 1992, Scientific instrumentation and university research, Research Policy, 21, pp.381-390.

Rosenberg, N. and Nelson, R. R., 1994, American universities and technical advance in industry, Research Policy, Vol. 23, pp. 323-348.

Schumpeter, J.A., 1912, The Economic Theory of Development, Oxford University Press: Oxford.

Senker, J. and Faulkner, W., 1992, Industrial use of public sector research in advanced technologies: a comparison of biotechnolgies and ceramics, $R \& D$ Management, 22, pp.157-175. 
Silverberg, G., 1984, Embodied technical progress in a dynamic economic model: the self-organisation paradigm, in Nonlinear Models of Fluctuating Growth, R. Goodwin, M. Krüger and A. Vercelli (eds.), Springer-Verlag: Berlin, Heidelberg, New York.

Silverberg, G., 1987, Technical progress, capital accumulation and effective demand: a self-organisation model, in Economic Evolution and Structural Adjustment, D. Batten, J. Casti and B. Johansson (eds.), Springer-Verlag: Berlin, Heidelberg, New York.

Silverberg, G., Dosi, G. and Orsenigo, L., 1988, Innovation, diversity and diffusion: a self-organising model, The Economic Journal, 98, pp.1032-1054.

Stuart, T.E., Hoang, H. and Hybels, R., 1999, Inter-organizational endorsements and the performance of entrepreneurial ventures, Administrative Science Quarterly, 44, pp.315350.

Swann, P., 1996, 'The economic value of publicly funded research', Report for DTI, April 1996, PREST, University of Manchester: Manchester.

Szulanski, G., 1996, Exploring internal stickiness: impediments to the transfer of best practice within the firm, Strategic Management Journal, 17, pp.27-43.

Tyler, B.B. and Steensma, H.K., 1995, Evaluating technological collaborative opportunities: a cognitive modelling perspective, Strategic Management Journal, 16, pp.43-70.

Utterback, J., 1994, Mastering the Dynamics of Innovation, Harvard Business School Press, Boston, MA.

Weidlich, W. and Haag, G., 1983, Concepts and Models of a Quantitative Sociology, Springer-Verlag: Berlin, Heidelberg, New York.

Weisbuch, G., Kirman, A. and Herreiner, D., 2000, Market organisation and trading relationships, The Economic Journal, 110, pp.411-436.

Williamson, O.E., 1975, Markets and Hierarchies: Analysis and Anti-trust Implications, Free Press: New York.

Williamson, O.E., 1981, The economics of organisation: the transactions cost approach, American Journal of Sociology, 87, pp.548-577.

Williamson, O.E., 1983, Credible commitments: using hostages to support exchange, American Economic Review, 73, pp.519-540.

Williamson, O.E., 1991, Comparative economic organization: the analysis of discrete structural alternatives, Administrative Science Quarterly, 36, pp.269-296. 
Windrum, P. and Birchenhall, C., 1998, Is life cycle theory a special case?: dominant designs and the emergence of market niches through co-evolutionary learning, Structural Change and Economic Dynamics, 9, pp.109-134.

Witt, U., 1987, Individualistische Grundlagen der Evolutorischen Ökonomik, Mohr Siebeck : Tübingen.

Yoshino, M.Y. and Rangan, U.S., 1995, Strategic Alliances: An Entrepreneurial Approach to Globalization, Harvard Business School Press, Boston, MA. 